Jrought about reflexly by cold, moving, moist air, and want of radiant heat, may produce pain in joints which are not normal, but exposed to some toxic zgent the power of which is increased by a lessening of the oxygen supply. In those living a sedentary ife, the circulation is very deficient in muscles and joints which are very little used.

London Light and Electrical Clinic, LeONaRd Hill. S.W.1.

\section{Distribution of the Polychæte Worm, Syllis ramosa, McIntosh}

IT is generally admitted that one of the most remarkable forms of life discovered by the Challenger expedition is the polychæte worm, Syllis ramosa, in which the body branches laterally, these branches again sending off shoots into the passages of the sponge in which the worm lives. The result is an intricate net-work (except that, of course, the branches do not anastomose), and as each branch ends in an anus there is a large number of ani to one head. The two specimens obtained by the Challenger lived in the bases of hexactinellid sponges found at 140 fathoms depth in the Arafura Sea and in the Philippines at 95 fathoms.

Mr. C. C. A. Monro of the British Museum, in a letter to me, writes: "I have not searched the literature thoroughly but as far as I know, Syllis ramosa has not been seen since the 'Challenger' except off the Japanese coast, where it appears to be moderately common. It was found by Izuka in Sagami Bay in about $100 \mathrm{fms}$. and in. Struga Bay in 90 fms., usually in a Hexactinellid sponge (Crateromorpha meyeri rugosa)."

Its appearance in the northern Red Sea at a depth of one fathom is therefore worth noting. I obtained it from a small sponge about $10 \mathrm{~mm}$. in diameter which was attached to a dead branch of the coral Lobophyllia corymbosa, on the edge of a small coral reef about $100 \mathrm{yd}$. from the laboratory of the Biological Station of the University of Egypt, at Ghardaqa (known to the oil companies, and marked on some maps, as "Hurghada"), just south of the entrance to the Gulf of Suez.

The method of its discovery is also worth describing, as it is the only way in which the bulk of the smaller fauna inhabiting any material can be obtained. A bucket full of the material, in this case, dead branches of Lobophyllia, is kept overnight in water to which a handful of magnesium sulphate is added as a narcotic. This causes burrowing and cranny-loving forms to emerge, and on going over the material, 12 to 24 hours later according to the temperature, these may be rinsed or picked off each piece of stone, shell, coral or weed. At the bottom of the bucket remains a considerable bulk of small life, principally Crustacea and Polychæta, with Mollusca, planarians, small echinoderms, sipunculids, etc. This can be washed in old spirit, decanted from sand, and bottled for future examination. As an indication of the difference which would have been made to the older collections had this method been used, I may mention the Staurocephalidæ, small and particularly beautiful Polychæta, which figure in about one collection in twenty. Here, and elsewhere, I have found them in one or two cases by ordinary collecting, but by 'washing out' I find them frequently in fair numbers. In the present case on finding in my 'washing' two small pieces of Syllis ramosa, I worked over the material again and soon found the little fragile siliceous sponge in which is the remainder of the worm. I have not attempted to dissect out the head and have not found any sexual buds, preferring to make a thorough search when I have more material. Of its specific identity with Syllis ramosa, I have no doubt.

Cyril Crossland.

(Director.)
Marine Biological Station, Ghardaqa,
Red Sea District, Egypt.
Jan. 24.

\section{A Dodecapodous Pycnogonid}

IN a letter published in NATURE for July 28, 1910 , I directed attention to Prof. E. L. Bouvier's discovery of Pentapycnon and discussed its relation to the other two genera of decapodous Pycnogonida. I am now able to announce the even more surprising discovery of an antaretic pycnogonid with six pairs of legs.

A few days ago, Sir Douglas Mawson handed over the Pycnogonida obtained on his latest antarctic expedition to be worked out by my colleague, Dr. Isabella Gordon. Among these is a magnificent specimen spanning 19 inches from tip to tip of its outstretched legs. So far as our preliminary examination has gone, it appears to differ from the two species of Decolopoda in no important respect except that it has an additional pair of legs. Exact particulars of the locality where the specimen was taken are not yet available, but it was dredged at a depth of 219 metres in the region of the antarctic lying to the south of Australia.

Dr. Gordon and I propose to describe this remarkable new form in detail elsewhere and to discuss its bearing on the problems of pycnogonid phylogeny. It need only be said at present that it appears to offer no obstacle to the view, which I have previously advocated, that the decapodous (and now the do. decapodous) Pycnogonida have been derived from octopodous forms, and that the Pycnogonida as a whole may conceivably owe their origin to an analogous disturbance of the established metameric pattern of the normal Arachnida.

British Museum (Natural History),

$$
\text { W. T. Calman. }
$$

Cromwell Road, S.W.7.

Feb. 13.

\section{The Second Piltdown Skull}

Is his work on "The Skeletal Remains of Early Man" (Smithsonian Miscellaneous Collections, vol. 83, 1930), Dr. Aleš Hrdlička doubts my statement that the late Charles Dawson discovered the isolated lower molar tooth of Eoanthropus with the remains of the second skull in the Piltdown gravel. Fortunately, among old correspondence, I have just found a postcard of July 30, 1915, written by Mr. Dawson, in which he announces his discovery of this molar tooth "with the new series". I have given the postcard to the Geological Department of the British Museum (Natural History), so that the record may be preserved and made available for reference.

\section{ARThUR SmITH Woodward.}

Hill Place,

Haywards Heath, Sussex. 